\title{
Perda de nitrogênio pela parte aérea de plantas de trigo
}

\author{
Nitrogen loss through above-ground parts of wheat plants
}

\author{
Isabela Rodrigues Bologna ${ }^{{ }^{*}}$ Carlos Eduardo Faroni ${ }^{1}$ \\ Anderson Lange ${ }^{2}$ Paulo Cesar Ocheuze Trivelin ${ }^{2}$
}

\section{RESUMO}

A forma mais conhecida de saída de nitrogênio dos agroecossistemas é a perda por volatilização de amônia do solo; entretanto, um ponto pouco avaliado e quantificado é a perda de amônia pela parte aérea dos vegetais. Neste contexto, conduziu-se um experimento com objetivo de quantificar alterações nas quantidades de nitrogênio, em diferentes estádios de desenvolvimento da cultura do trigo, como indicativo de possíveis perdas de amônia pela parte aérea. O delineamento experimental foi o inteiramente casualizado, num esquema fatorial $2 \times 3$ (dois níveis de $N$ : 180 e 300mg de $N$ vaso $^{-1}$, e três épocas de colheita: pré-antese, pósantese e maturidade), com quatro repetições, totalizando 24 parcelas. Utilizaram-se vasos contendo $4 \mathrm{~kg}$ de um Latossolo Vermelho distrófico típico. A fertilização nitrogenada foi realizada com sulfato de amônio marcado a $3 \%$ em átomos de ${ }^{15} \mathrm{~N}$. Foram verificadas reduções do $\mathrm{N}$ do fertilizante acumulado nas plantas de trigo, que podem estar relacionadas às perdas de $\mathrm{N}-\mathrm{NH}$ pela parte aérea. Essas perdas foram de $25 \mathrm{mg} \mathrm{vaso}^{-1}$ (aproximadamente $12 \mathrm{~kg} \mathrm{ha}$ de N) e $36 \mathrm{mg} \mathrm{vaso}^{-1}$ (aproximadamente $18 \mathrm{~kg} \mathrm{ha}^{-1}$ de $\mathrm{N}$ ) no menor e no maior nível de fertilização, respectivamente. As maiores perdas ocorreram na pós-antese e na maturidade, com 8,4 e 6,8\% do $N$ total aplicado para a menor e a maior dose.

Palavras-chave: ${ }^{15} \mathrm{~N}$, emissão de amônia, ciclo do nitrogênio.

\section{ABSTRACT}

The most well-known way of nitrogen loss from agricultural ecosystems is the volatilization of ammonia from soil. However, nitrogen loss through above-ground parts of plants is one issue not well-known and not so much evaluated and quantified. In this way one experiment was carried out with the aim of quantifying nitrogen in different growth stages of wheat plants as an indicator of nitrogen losses through above- ground parts. The experimental design was completely randomized with factorial $2 \times 3$ (two nitrogen rates: 180 and $300 \mathrm{mg}$ of nitrogen per pot, and three harvest times: pre-anthesis, post-anthesis and physiological maturity) with four repetitions, totalizing 24 plots. Pots were used contained $4 \mathrm{~kg}$ of Rhodic Hapludox. The nitrogen source was ammonium sulphate labeled with 3 atoms \% of ${ }^{15} \mathrm{~N}$. Aderease of $N$ derived from fertilizer $-{ }^{15} \mathrm{~N}$ in the wheat plants were verified and can be related to the $\mathrm{NH}_{3}-\mathrm{N}$ losses from the aerial part of the plants. These losses represented about $25 \mathrm{mg}$ per pot (approximately $12 \mathrm{~kg} \mathrm{~N}$

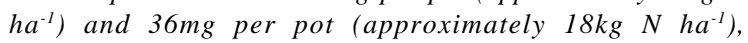
respectively, for the $N$ rates: 180 and $300 \mathrm{mg} N$ per pot. The highest losses were verified during both stages of post-anthesis and maturity, with 8.4 and $6.8 \%$ of total nitrogen applied to the lowest and the highest applied doses.

Key words: ${ }^{15} \mathrm{~N}$, ammonia emmission, nitrogen cycle.

\section{INTRODUÇÃO}

O ciclo biogeoquímico do nitrogênio, que se refere à cadeia de reações de oxirredução do elemento, é um dos mais discutidos devido à sua complexidade e dinâmica. As diversas vias de transferência entre compartimentos de um agroecossistema (entradas e saídas), bem como suas taxas, são bem descritas e contabilizadas.

Umas das formas mais conhecidas de saída de nitrogênio do sistema é a perda por volatilização de amônia do solo, porém um ponto ainda obscuro e pouco avaliado e quantificado são as perdas do elemento na forma de amônia pela parte aérea dos vegetais. Essa

${ }^{1}$ Departamento de Solos e Nutrição de Plantas, Escola Superior de Agricultura “Luiz de Queiroz” (ESALQ/USP), Piracicaba, SP, Brasil. *Autor para correspondência. Av. Centenário, 303, CP 96, 13400-970, Laboratório de Isótopos Estáveis (CENA/USP). Email: irbologn@esalq.usp.br.

${ }^{2}$ Laboratório de Isótopos Estáveis, Centro de Energia Nuclear na Agricultura (CENA/USP), Piracicaba, SP, Brasil. 
via de saída do nitrogênio tem sido citada como contribuidora no aumento dos níveis de amônia da atmosfera (SUTTON et al., 1993), sendo responsável por $15-20 \%$ do total das emissões gasosas de $\mathrm{NH}_{3}$ (ASMAN et al., 1998). SUTTON et al. (1993) citaram medidas micrometeorológicas que evidenciaram valores de emissões pelos vegetais na faixa de $5-15 \mathrm{~kg} \mathrm{ha}^{-1} \mathrm{ano}^{-1}$ de $\mathrm{N}-\mathrm{NH}_{3}$.

Para a cultura da cevada, SCHJOERRING et al. (1993) encontraram perdas de $1-2 \mathrm{~kg} \mathrm{ha}^{-1} \mathrm{ano}^{-1}$ de N$\mathrm{NH}_{3}$ em três níveis de fertilização com nitrogênio. HARPER et al. (1987) observaram maiores perdas de $\mathrm{NH}_{3}$ pela parte aérea da cultura do trigo de inverno, cerca de $8 \pm 2 \mathrm{~kg} \mathrm{ha}^{-1}$ ano $^{-1}$ de $\mathrm{N}-\mathrm{NH}_{3}, 20$ dias após a adubação nitrogenada e $7 \pm 1,5 \mathrm{~kg} \mathrm{ha}^{-1}$ ano $^{-1}$ de $\mathrm{N}-\mathrm{NH}_{3}$, no período entre a antese e a colheita, totalizando cerca de $15 \mathrm{~kg} \mathrm{ha}^{-1}$ ano $^{-1}$ de $\mathrm{N}-\mathrm{NH}_{3}$ em um ciclo de plantio da cultura.

Vários são os fatores que influenciam a ocorrência e a magnitude da perda de nitrogênio pela parte aérea das plantas, destacando-se: $\mathrm{pH}$ e temperatura foliar, velocidade dos ventos e transpiração, nutrição em nitrogênio, condições de luz e escuro, estresse ambiental e ocorrência de doenças, e, ainda, uma das condições mais importantes, idade da planta e suas condições de senescência (HOLTANHARTWING \& BOCKMAN, 1994). Segundo MORGAN \& PARTON (1989), nos estágios reprodutivos, há aumento do potencial de volatilização da amônia devido às mudanças no metabolismo do nitrogênio da planta e também por meio da quebra de proteínas e aminoácidos. HARPER et al. (1987) evidenciaram, por meio do uso do traçador ${ }^{15} \mathrm{~N}$, que, após a antese do trigo, metade do nitrogênio do grão proveio da remobilização do nitrogênio armazenado nos caules e folhas durante o processo da quebra de proteínas e aminoácidos, no período de maturação das folhas e caules, sendo a outra metade vinda diretamente do solo.

A maioria dos métodos de estimativa das perdas de $\mathrm{N}$ por volatilização da parte aérea dos vegetais é considerada de grande complexidade, tais como métodos de confinamento de plantas e o micrometereológico, e até mesmo o de determinação indireta, tal como o de quantificação do nitrogênio na parte aérea das plantas (HOLTAN-HARTWING \& BOCKMAN, 1994). Segundo WETSELAAR \& FARQUHAR (1980), o método de quantificação indireta não considera a perda da amônia por outras vias, tais como a translocação para as raízes, as perdas por exsudações radiculares, lixiviações e desnitrificações

O uso da técnica isotópica com o traçador ${ }^{15} \mathrm{~N}$ permite a sofisticação do método da quantificação de nitrogênio, pois ao fertilizar uma planta com adubo marcado em ${ }^{15} \mathrm{~N}$, as condições de rastreamento do nitrogênio $\left({ }^{15} \mathrm{~N}\right)$ são reais, inferindo-se o total utilizado pela planta e o presente no solo após o ciclo da cultura.

O objetivo deste trabalho foi quantificar as alterações nas quantidades de nitrogênio em diferentes estádios de desenvolvimento de plantas de trigo como indicativo de possíveis perdas pela parte aérea da cultura, por volatilização de amônia.

\section{MATERIAL E MÉTODOS}

O trabalho foi desenvolvido em casa-devegetação, no Centro de Energia Nuclear na Agricultura - CENA/USP, Piracicaba, SP, entre outubro a dezembro de 2003. O trabalho foi realizado em parcelas (vasos) contento $4 \mathrm{~kg}$ de solo de terra fina seca ao ar (TFSA), classificado como Latossolo Vermelho distrófico típico. As características químicas do solo na profundidade 0-20cm foram as seguintes: 4,9 $\mathrm{pH}\left(\mathrm{CaCl}_{2}\right)$; $8 \mathrm{~g} \mathrm{~kg}^{-1}$ M.O.; $1 \mathrm{mg} \mathrm{dm}^{-3}$ de $\mathrm{P}$ (resina), K, Ca, Mg e $\mathrm{H}+\mathrm{Al}: 1,4,6$, 3 e $16 \mathrm{mmol} \mathrm{dm}^{-3}$, respectivamente.

Foram aplicados óxidos de cálcio e magnésio com o intuito de elevar a saturação por bases ao nível de $70 \%$. O solo permaneceu incubado por 15 dias, sendo regularmente irrigado com o intuito de mantê-lo com $60 \%$ da máxima capacidade de retenção de água.

Após o período de incubação, foi realizada a adubação com $\mathrm{P}$ (superfosfato simples-SPS) e K (cloreto de potássio-KCl p.a), respectivamente, nas doses de $1 \mathrm{~g}_{2} \mathrm{O}_{5}$ e $0,5 \mathrm{~g} \mathrm{~K}_{2} \mathrm{O}$ por parcela. O SPS foi moído e aplicado, incorporando-o em superfície, e o KCl p.a. foi aplicado em solução na superfície do solo, parcelando-se metade da dose na semeadura do trigo, e a outra metade sete dias depois (no desbaste das plantas).

A semeadura foi realizada no dia 2 de outubro de 2003, utilizando-se por vaso 10 sementes de trigo (Triticum aestivum L.) do cultivar "IAC-24". Após a germinação plena (sete dias após a semeadura), foi realizado o desbaste, deixando-se quatro plantas por vaso.

O delineamento experimental foi 0 inteiramente casualizado, em esquema fatorial $2 \times 3$ (duas doses de $\mathrm{N}$ e três épocas de colheita) com quatro repetições, totalizando 24 parcelas. Os tratamentos foram: T1- 180mg $\mathrm{N}$ vaso ${ }^{-1}$ e colheita em pré-antese, T2-300mg N vaso ${ }^{-1}$ e colheita em pré-antese, T3- 180mg $\mathrm{N}$ vaso ${ }^{-1}$ e colheita em pós-antese, T4- 300mg N vaso${ }^{1}$ e colheita em pós-antese, T5- $180 \mathrm{mg} \mathrm{N}$ vaso $^{-1}$ e colheita na maturidade e T6- 300mg $\mathrm{N}$ vaso ${ }^{-1}$ e colheita na maturidade. As doses de nitrogênio de 180 e 300 (mg vaso $^{-1}$ de N) foram calculadas com a finalidade de se comparar a aplicação em campo de 90 e $150 \mathrm{~kg} \mathrm{~N} \mathrm{ha}^{-1}$, 
respectivamente, valores esses considerados elevados quando comparados aos recomendados para a cultura de trigo no Estado de São Paulo (CAMARGO et al., 1997).

A adubação nitrogenada foi realizada com sulfato de amônio marcado a $3 \%$ em átomos de ${ }^{15} \mathrm{~N}$. Nos tratamentos, o adubo com $\mathrm{N}$ foi aplicado na forma de solução, na superfície do solo, sendo a dose parcelada em duas épocas no desbaste e após sete dias da primeira aplicação.

A umidade do solo foi mantida a $60 \%$ da capacidade máxima de retenção de água por meio de irrigações controladas por pesagem dos vasos. Foram também coletadas e armazenadas todas as folhas que porventura se destacaram das plantas durante o período experimental, para que não houvesse perda desse material.

A colheita das plantas foi realizada observando-se os estádios definidos nos tratamentos, ou seja, pré-antese (45 dias após semeadura), pósantese (55 dias após semeadura) e maturidade plena (70 dias após semeadura). Na colheita, procedeu-se a amostragem da parte aérea e do sistema radicular, na pré e pós-antese, e também das panículas na plena maturidade. Em cada uma das amostras, determinou-se a massa do material úmido e posteriormente a massa de material seco em estufa. As amostras da parte aérea, raízes e panícula foram trituradas em moinho tipo Wiley e realizadas as determinações de $\mathrm{N}$ total e de abundância de ${ }^{15} \mathrm{~N}$ (\% em átomos) em espectrômetro de massas contendo analisador automático de $\mathrm{N}$, modelo ANCA-SL, 20-20, da PDZ Europa (Krewe, UK). O solo de cada vaso também foi amostrado, seco ao ar (TSA) e realizadas as determinações de $\mathrm{N}$ total e ${ }^{15} \mathrm{~N}$, além da umidade a $105^{\circ} \mathrm{C}$.

A recuperação do nitrogênio na planta ou no solo (mg vaso-1 de $\mathrm{N}$ ) proveniente da fonte nitrogenada, sulfato de amônio, (Nppf), foi calculada pela expressão:

Nppf $=[(\mathrm{a}-\mathrm{c}) /(\mathrm{b}-\mathrm{c})] \mathrm{N}$-total $\quad$ onde:

Nppf - Nitrogênio na planta ou solo proveniente da fonte- ${ }^{15} \mathrm{~N}$, sulfato de amônio, (mg vaso ${ }^{-1}$ );

a - Abundância de ${ }^{15} \mathrm{~N}$ (\% em átomos) na planta ou solo;

b - Abundância de ${ }^{15} \mathrm{~N}$ na fonte (3\% em átomos de ${ }^{15} \mathrm{~N}$ ); c- Abundância de ${ }^{15} \mathrm{~N}$ na planta ou solo no controle sem aplicação de adubo- ${ }^{15} \mathrm{~N}$;

$\mathrm{N}$-total - Conteúdo de nitrogênio na planta ou solo (mg vaso $^{-1}$ ).

A recuperação percentual na planta e no solo do $\mathrm{N}$ da fonte sulfato de amônio foi calculada como:

$\% \mathrm{R}=(\mathrm{Nppf} / \mathrm{D}) * 100$

significando D a dose de $\mathrm{N}$ aplicada com sulfato de amônio.

Os resultados foram submetidos à análise de variância em delineamento inteiramente casualizado. O teste de Tukey $(\alpha=0,10)$ foi usado na comparação das médias dos tratamentos.

\section{RESULTADOS E DISCUSSÃO}

No que se refere ao desenvolvimento do trigo avaliado por meio da produção de matéria seca da planta toda (parte aérea + raízes), o aumento da dose de $\mathrm{N}$ não proporcionou efeito significativo no acúmulo de matéria seca. Entretanto, foi observada influência do estádio fisiológico da cultura, sendo maior o acúmulo de matéria seca nos estádios mais avançados (Tabela 1).

Tabela 1 - Matéria seca e nitrogênio total na planta toda de trigo (parte aérea + raiz) com os níveis de N e os estádios fisiológicos de colheita. Média de quatro repetições.

\begin{tabular}{|c|c|c|c|c|c|c|}
\hline \multirow{2}{*}{ Dose N } & \multicolumn{3}{|c|}{ Matéria seca } & \multicolumn{3}{|c|}{$\mathrm{N}$ total } \\
\hline & $\mathrm{PA}^{1}$ & $\mathrm{PO}^{1}$ & $\mathrm{MA}^{1}$ & PA & $\mathrm{PO}$ & MA \\
\hline \multicolumn{7}{|c|}{ mg vaso $^{-1}$} \\
\hline 180 & 5375 & 8400 & 10450 & $196,1 \mathrm{cB}$ & $229,4 \mathrm{aB}$ & $199,2 \mathrm{bB}$ \\
\hline 300 & 5925 & 8275 & 12350 & $246,6 \mathrm{cA}$ & $262,9 \mathrm{bA}$ & $296,1 \mathrm{aA}$ \\
\hline Média & $5650 c$ & 8337b & $11400 a$ & $221,3^{\mathrm{ns}}$ & $246,1^{\mathrm{ns}}$ & $247,6^{\text {ns }}$ \\
\hline $\mathrm{F}_{\text {dose }}$ & & $2,6^{\mathrm{ns}}$ & & & $27,7^{*}$ & \\
\hline$F_{\text {época }}$ & & $48,7^{*}$ & & & $2,2^{\mathrm{ns}}$ & \\
\hline $\mathrm{F}_{\text {dose*época }}$ & & $1,6^{\mathrm{ns}}$ & & & $2,7^{*}$ & \\
\hline C.V.(\%) & & 13,78 & & & 11,78 & \\
\hline
\end{tabular}

${ }^{1}$ PA, PO e MA significam os estádios fisiológicos de colheita de pré-antese, pós-antese e maturidade fisiológica, respectivamente.

* e ns: significativo e não-significativo a 10\%, respectivamente. Médias dos fatores PA, PO e MA seguidas de letras minúsculas distintas, bem como médias dos fatores 180 e 300 seguidas de letras maiúsculas distintas, diferem significativamente pelo teste de Tukey ( $\mathrm{p}=0,10)$

Ciência Rural, v.36, n.4, jul-ago, 2006. 
Para a quantidade acumulada de nitrogênio na planta toda, observou-se que, no menor nível de adubação nitrogenada (180 $\mathrm{mg}$ vaso $^{-1}$ ), o maior acúmulo de nitrogênio ocorreu no estádio de pós-antese, com queda nesse valor na plena maturidade fisiológica (Tabela 1). Provavelmente, esses resultados já indicaram possível perda de nitrogênio da planta para a atmosfera, uma vez que o $\mathrm{N}$-total do sistema radicular foi incluído no nitrogênio total da planta toda, sendo descartada, portanto, uma possível translocação de nitrogênio para o sistema radicular. Com 300mg vaso-1 de $\mathrm{N}$, não foi observada tendência ao maior acúmulo de $\mathrm{N}$ no estádio de pré-antese, o que pode ser explicado pelo fato de esse tratamento ter influenciado no prolongamento do estádio vegetativo da planta, retardando, assim, a maturidade. Ressalta-se que a colheita no estádio de maturidade fisiológica foi realizada, para ambas as doses de nitrogênio, em mesma data. Como na maior dose de nitrogênio as plantas tiveram o ciclo estendido, o que foi observado pelo aspecto visual das plantas, ao se manterem verdes por mais tempo, a maior dose de $\mathrm{N}$ pode ter influenciado diretamente na senescência da cultura e na perda de $\mathrm{N}$ pela parte aérea da planta, uma vez que é sabido que o estímulo à perda de $\mathrm{N}$ por esta via é influenciado pelo estado de senescência da planta (MORGAN \& PARTON, 1989). Outro fator a ser observado, conforme PARTON et al. (1988), refere-se às emissões de $\mathrm{NH}_{3}$ da parte aérea para a atmosfera, que aumentam com o teor de $\mathrm{N}$ das folhas, o que, no caso deste experimento, pode ter sido suprimido pelo prolongamento do estádio vegetativo do trigo.

Os resultados anteriores são confirmados pelos de nitrogênio na planta proveniente do fertilizante, na planta toda (Nppf) (Tabela 2). No tratamento com dose de $180 \mathrm{mg}$ vaso $^{-1}$ de $\mathrm{N}$, houve redução no Nppf, do estádio de pós-antese para a maturidade fisiológica, com conseqüente queda nos valores de recuperação do N-sulfato de amônio na planta, de 77,1 para 69,3\%. Com o incremento no nível de fertilização nitrogenada, houve aumento proporcional do Nppf; entretanto, a porcentagem de recuperação do fertilizante na planta foi menor para a maior dose de $\mathrm{N}$ nos estádios de pré- antese e pósantese. A maior recuperação na maturidade fisiológica, na dose de $300 \mathrm{mg}$ vaso $^{-1}$, reforça a idéia de que a maior disponibilidade de nitrogênio proporcionou extensão do ciclo vegetativo do trigo, desfavorecendo a perda de N pela parte aérea. Outro fator a ser considerado é que o maior valor médio de recuperação na dose de 300mg vaso ${ }^{-1}$ de $\mathrm{N}(72,3 \%)$ foi obtido no estádio de maturidade fisiológica e, mesmo assim, foi numericamente menor que a maior recuperação da menor dose de $\mathrm{N}$ (77,1\%), verificada já no estágio de pós-antese.

Embora na maior dose de fertilização nitrogenada (300mg vaso ${ }^{-1}$ ) não tenha sido observada diminuição no Nppf do estádio de pré-antese para maturidade, fato que poderia ser justificado conforme o ocorrido para a menor dose, a perda de nitrogênio pela parte aérea da cultura, quando se comparou os valores de Nppf com o recuperado no solo (Tabela 2), registrou-se queda de recuperação no solo da pósantese para a maturidade de, em média, $16 \%$. Considerando-se que a diminuição na recuperação no solo significa maior utilização do $\mathrm{N}$ da adubação nitrogenada pela planta, com reflexo de incremento nos valores de Nppf, uma perda média de 16\% na

Tabela 2 - Nitrogênio na planta toda proveniente do fertilizante e \% de recuperação do nitrogênio na planta toda de trigo (parte aérea + raiz) e no solo. Média de quatro repetições.

\begin{tabular}{|c|c|c|c|c|c|c|c|c|c|}
\hline \multirow{2}{*}{ Dose $\mathrm{N}$} & \multicolumn{3}{|c|}{ Nppf } & \multicolumn{3}{|c|}{ Recuperação planta } & \multicolumn{3}{|c|}{ Recuperação solo } \\
\hline & $\mathrm{PA}^{1}$ & $\mathrm{PO}^{1}$ & $\mathrm{MA}^{1}$ & PA & $\mathrm{PO}$ & MA & PA & $\mathrm{PO}$ & MA \\
\hline \multicolumn{4}{|c|}{ 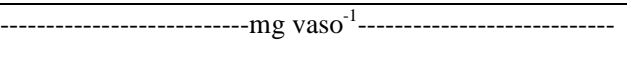 } & \multicolumn{6}{|c|}{ 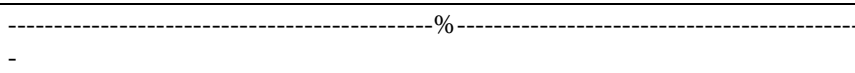 } \\
\hline 180 & $120,5 \mathrm{cB}$ & $138,8 \mathrm{aB}$ & $124,7 \mathrm{bB}$ & 66,9cA & $77,1 \mathrm{aA}$ & $69,3 \mathrm{bB}$ & $31,3 \mathrm{aB}$ & $20,9 b B$ & $20,4 \mathrm{cA}$ \\
\hline 300 & $182,6 \mathrm{cA}$ & 189,1bA & $217,0 \mathrm{aA}$ & $60,9 \mathrm{cB}$ & $63,0 \mathrm{bB}$ & $72,3 \mathrm{aA}$ & $37,9 \mathrm{aA}$ & 33,7bA & $17,6 \mathrm{cB}$ \\
\hline Média & 151,5 & 163,9 & 170,8 & 63,9 & 70,0 & 70,8 & 34,6 & 27,3 & 19,0 \\
\hline $\mathrm{F}_{\text {dose }}$ & & $123,8^{*}$ & & & $5,0^{*}$ & & & $4,2^{*}$ & \\
\hline$F_{\text {época }}$ & & $3,4^{*}$ & & & $2,9^{*}$ & & & $11,0^{*}$ & \\
\hline $\mathrm{F}_{\text {dose*época }}$ & & $4,1^{*}$ & & & $3,8^{*}$ & & & $2,8^{*}$ & \\
\hline C.V.(\%) & & 9,26 & & & 9,10 & & & 24,52 & \\
\hline
\end{tabular}

${ }^{1} \mathrm{PA}$, PO e MA significam os estádios fisiológicos de colheita de pré-antese, pós-antese e maturidade fisiológica, respectivamente. *: significativo a 10\%. Médias dos fatores PA, PO e MA seguidas de letras minúsculas distintas, bem como médias dos fatores 180 e 300 seguidas de letras maiúsculas distintas, diferem significativamente pelo teste de Tukey $(p=0,10)$.

Ciência Rural, v.36, n.4, jul-ago, 2006. 
recuperação pelo solo entre a pós-antese e a maturidade refletiria em incremento de 48mg de $\mathrm{N}$ (para uma dose aplicada de 300mg vaso-1) nos valores de Nppf entre esses dois estádios. Entretanto, esse incremento não foi observado entre os estádios, pois o Nppf observado na maturidade foi de $217 \mathrm{mg} \mathrm{N}$, sendo que seria esperado um total de 237mg de $\mathrm{N}$, resultante da soma do Nppf do estádio de pós-antese (189,1mg N) e dos 16\% de queda na recuperação no solo (48mg N). Esses resultados demonstram que, mesmo não havendo diminuição nos valores de Nppf entre os estádios do tratamento de maior fertilização nitrogenada, o acréscimo do Nppf não foi proporcional à redução do $\mathrm{N}$ não recuperado no solo, podendo-se inferir que houve perda de nitrogênio do sistema na ordem de $20 \mathrm{mg} \mathrm{vaso}^{-1}$, ou seja, $10 \mathrm{~kg}$ ha $^{-1}$ de $\mathrm{N}$, devido à volatilização, possivelmente, pela parte aérea das plantas.

Os resultados de \% de recuperação no sistema solo-planta (Figura 1) indicaram efeito da época (estádio fisiológico no momento da colheita) no total do N-sulfato de amônio recuperado no sistema. Em ambos os níveis de adubação nitrogenada observouse que, do estádio de pré-antese até a maturidade fisiológica, houve queda no percentual recuperado, em média de 8,4 e 6,8\%. Isso significa que, para a aplicação de nitrogênio de $180 \mathrm{mg} \mathrm{vaso}^{-1}$ houve perda entre estes dois estádios fisiológicos de 15,1 $\mathrm{mg}_{\text {vaso }}{ }^{-1}$ de N (7,6kg $\mathrm{ha}^{-1}$ ) e, para a aplicação de $300 \mathrm{mg}$ vaso $^{-1}$, perda de 20,4mg (10,2kg ha-1). Deve-se considerar também que, no maior nível de fertilização, ocorreram diminuições na recuperação do $\mathrm{N}$ no sistema solo-planta de $2 \%$ da fase de pré para pós-antese, resultando em perda acumulada de nitrogênio na ordem de $26,4 \mathrm{mg}$ vaso $^{-1} \mathrm{de}$ $\mathrm{N}\left(13,2 \mathrm{~kg} \mathrm{ha}^{-1}\right)$.

É importante salientar que esses valores contabilizam somente a perda do nitrogênio originária

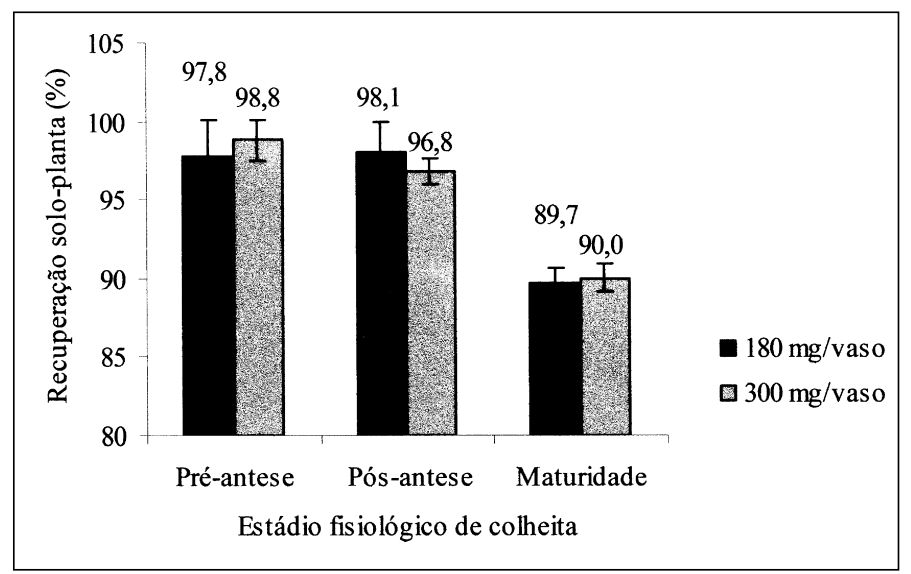

Figura 1 - Recuperação percentual no sistema solo-planta com o nível de $\mathrm{N}$ e época de colheita de plantas de trigo do fertilizante, ou seja, do sulfato de amônio. Caso seja considerada a relação Ndff : Ndfs (nitrogênio derivado da fonte fertilizante e do solo, respectivamente), encontram-se relações médias de 1,6:1 e 2,7:1 para a menor e a maior dose, respectivamente. Assim, podese estimar as perdas de $\mathrm{N}$-total para a menor e maior dose como sendo de $24,5 \mathrm{mg}$ vaso $^{-1}$ de $\mathrm{N}\left(12,3 \mathrm{~kg} \mathrm{ha}^{-1}\right) \mathrm{e}$ de $36,2 \mathrm{mg}$ vaso $^{-1}$ de $\mathrm{N}\left(18,1 \mathrm{~kg} \mathrm{ha}^{-1}\right)$.

Esses resultados apontam para uma perda de nitrogênio do sistema solo-planta, a qual pode estar relacionada às perdas de nitrogênio como amônia pela parte aérea da cultura, uma vez que outras possíveis formas de perda de nitrogênio do sistema foram controladas. As possíveis ocorrências de volatilização de $\mathrm{NH}_{3}$ do solo, da fonte nitrogenada, são pouco prováveis, pois foi utilizado o sulfato de amônio aplicado em solução ao solo. As perdas por lixiviação são excluídas, uma vez que os vasos não possuíam sistema de drenagem e as irrigações foram feitas regularmente, a fim de manter a umidade do solo em torno de $60 \%$ da máxima capacidade de campo. As perdas do nutriente por desnitrificação também são pouco prováveis, uma vez que as condições preferenciais para sua ocorrência (ambiente redutor) foram evitadas, bem como a fonte utilizada para fertilização e o pH do solo não contribuem para tal ocorrência. SCHJOERRING \& MATTSON (2001), contabilizando as perdas de $\mathrm{N}$ da parte aérea do trigo de inverno por dois anos consecutivos, por meio do uso da técnica de medida do fluxo de amônia da atmosfera, observaram perdas de nitrogênio na ordem de 1,5 e $5 \mathrm{~kg} \mathrm{ha}^{-1}$. As diferenças nas emissões de $\mathrm{N}-\mathrm{NH}_{3}$ foram justificadas pelas diferenças de clima entre os dois anos consecutivos, uma vez que, no primeiro ano do experimento em campo, houve maior déficit hídrico, o que prejudicou a absorção no $\mathrm{N}$ do solo e o crescimento e desenvolvimento da cultura.

\section{CONCLUSÕES}

Ocorreram perdas do sistema solo-planta de trigo da ordem de $24,5 \mathrm{mg}$ vaso $^{-1}\left(12,3 \mathrm{~kg} \mathrm{ha}{ }^{-1}\right)$ e de $36,2 \mathrm{mg}$ vaso $^{-1}$ $\left(18,1 \mathrm{~kg} \mathrm{ha}^{-1}\right)$ respectivamente em dois níveis de fertilização com nitrogênio (180 e 300mg vaso-1 $^{-1}$ de $\mathrm{N}$ ), podendo essas estarem relacionadas às perdas do nitrogênio como $\mathrm{NH}$ pela parte aérea. As maiores perdas ocorrreram entre as fases de pós-antese e de maturidade fisiológica, com 8,4 e 6,8\% do nitrogênio total aplicado para a menor e para a maior dose, respectivamente.

Ciência Rural, v.36, n.4, jul-ago, 2006. 


\section{AGRADECIMENTOS}

Os autores agradecem aos discentes da disciplina CEN 5747-2 - Técnicas isotópicas em estudos de ciclagem de nitrogênio em agroecossistemas (CENA/USP), do ano de 2003, pelo auxílio no desenvolvimento da parte experimental: Camila Beij Jordão, Ciro Staino Manzoni, Cláudia Luciana Varnier, Eros Artur Bohac Francisco, Fernando César B. Zambrosi, Jack Fernando Santos Quispe, Marcos Emanuel Veloso, Maria Lígia de Souza Silva, Mariana Addison Pavei, Milene Mofatto.

\section{REFERÊNCIAS}

ASMAN, W.A.H. et al. Ammonia: emission, atmospheric transport and deposition. New Phytologist, Lancaster, n.139, p.27-48, 1998.

CAMARGO, C.E de O. et al. Trigo e triticale de sequeiro. In: RAIJ, B. van et al. (Ed). Recomendações de adubação e calagem para o Estado de São Paulo. Campinas: Fundação IAC, 1997. p.237-239. (Boletim, 100).

HARPER, L.A. et al. Nitrogen cycling in a wheat crop: soil plant and aerial nitrogen transport. Agronomy Journal, Madison, n.79, p.965-973, 1987.

HOLTAN-HARTWIG, L.; BOCKMAN, O.C. Ammonia exchange between crops and air. Norwegian Journal of
Agricultural Sciences, Norwegian, n.14, p.52-61, 1994. (supplement).

MORGAN, J.A.; PARTON, W.J. Characteristics of ammonia from spring wheat. Crop Science, Madison, n.29, p.726731, 1989.

PARTON, W.J. et al. Ammonia volatilization from spring wheat plants. Agronomy Journal, Madison, n.80, p.419425, 1988

SCHJOERRING, J.K. et al. Field investigations of ammonia exchange between barley plants and the atmosphere. I. Concentration profiles and flux densities of ammonia. Plant Cell Environment, Logan, n.16, p.161-167, 1993.

SCHJOERRING, J.K.; MATTSSON, M. Quantification of ammonia exchange between agricultural cropland and the atmosphere: Measurements over two complete growth cycles of oilssed rape, wheat, barley and pea. Plant and Soil, Dordrecht, n.228, p.105-115, 2001.

SUTTON, M.A. et al. The exchange of ammonia between the atmosphere and plant communities. Advances in Ecology Research, New York, n.24, p.301-393, 1993.

WETSELAAR, R.; FARQUHAR, G.D. Nitrogen losses from tops of plants. Advances in Agronomy, New York, n.23, p.263-302, 1980 